\title{
Acesso, expansão e eqüidade na educação superior: novos desafios para a política educacional brasileira ${ }^{1}$
}

CLARISSA ECKERT BAETA NEVES", LEANDBO RAIZER": ROCHELE FELLINI FACHINETTO:*:

Introdução

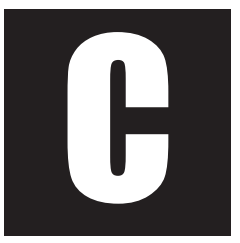

omo ampliar o acesso e alcançar uma maior eqüidade com uma formação de qualidade é uma questão central da política educacional. Na última década, foram propostas soluções referentes à ampliação do acesso e maior eqüidade através da diversificação do sistema, com a criação de novos tipos de IES, novos tipos e modalidades de cursos, bem como da proposta de políticas de inclusão social e de ações afirmativas (PROUNI e política de cotas). Diante deste cenário, o tema da democratização do acesso à educação superior de qualidade reveste-se de grande importância. A experiência que o Brasil vem vivendo com relação às transformações no âmbito

* Professora do PPG em Sociologia UFRGS, pesquisadora CNPq e Coordenadora do Grupo de Estudos sobre a Universidade/GEU/UFRGS ( www.ufrgs.br/geu). E-mail: clanev@ufrgs.br. Brasil. ** Doutorando PPG Sociologia/UFRGS. Bolsista CAPES. Pesquisador GEU/UFRGS; colaborador CEDCIS/UFRGS. E-mail: Iraizer2003@yahoo.com.br. Brasil.

***Mestranda PPG Sociologia/UFRGS. Pesquisadora GEU/UFRGS. E-mail: chelifellini@yahoo.com.br. Brasil.

1Este trabalho apresenta resultados da pesquisa realizada, durante os anos de 2005 e 2006, sobre acesso e eqüidade na educação superior e diversificação, com apoio do Edital Ciências Humanas e Sociais/CNPq. Os autores agradecem à leitura atenta e as contribuições do prof. Dr. Alexandre Virgínio. Leonardo Renner Koppe e Alexandre B. Rodrigues, bolsistas IC/CNPq, também colaboraram com a produção do artigo. 
Sociologias, Porto Alegre, ano 9, no 17, jan./jun. 2007, p. 124-157

da educação superior é muito rica e serve como importante referência para análise dos desafios da educação superior na sociedade contemporânea e, em particular, nos países em desenvolvimento. A análise dos dados revela o cenário atual: a ampliação do acesso, bem como a implantação das políticas de inclusão resultaram numa expansão especialmente pelo sistema privado. Isto ensejou uma situação controversa, uma vez que além do ensino ser pago favorecendo uma inclusão instável, a formação oferecida pelo sistema privado é muito criticada pela sua baixa qualidade.

Nesse sentido, a questão do acesso e da eqüidade na educação será discutida e analisada neste artigo, tendo por referência três aspectos básicos: a) o processo de expansão do ensino superior tem assegurado verdadeira democratização do acesso à educação superior de qualidade? b) em que medida a diferenciação da oferta de oportunidades de educação póssecundária e superior são instrumentos de democratização do acesso? c) como e em que extensão as políticas de inclusão social estimulam a democratização do acesso e a qualidade do ensino oferecido.

\section{O contexto macrossocial}

As transformações que vêm ocorrendo no contexto macrossocial e as possíveis conseqüências sobre o sistema educacional superior devem ser analisadas à luz de dois importantes processos, a saber, a globalização e a emergência da sociedade do conhecimento.

A globalização é um fenômeno complexo e multifacetado, sobretudo contraditório. Trata-se de um processo de integração das sociedades apresentando lados trágicos de desintegração dos Estados nacionais, desorientação social e cultural; e lados positivos de esperança e possibilidades de reorganização social e econômica da humanidade em um nível global (Fenzl, 2000:45). 
Sociologias, Porto Alegre, ano 9, no 17, jan./jun. 2007, p. 124-157

A globalização é um dado real, irreversível, caracterizando-se pela internacionalização e interdependência das economias nacionais no âmbito planetário. A globalização não é um processo consensual entre os estudiosos, mas um intenso campo de conflitos entre grupos sociais, Estados e interesses hegemônicos, de um lado, e grupos sociais e Estados e interesses subalternos, por outro. Está relacionada à emergência de uma nova divisão internacional do trabalho, baseada na globalização da produção levada a cabo pelas empresas multinacionais, que se projetam como atores centrais na nova economia mundial.

Este processo tem por conseqüência: a descapitalização das forças produtivas; a globalização das contradições sociais; a fragilização dos Estados Nacionais e, conseqüentemente, a desintegração do poder político dos protagonistas nacionais individuais. Em suma, trata-se da separação entre poder, econômico e transnacional, e política, pública e local (BAUMAN, 2000).

Giddens (1991:69), por sua vez, define a globalização como a "intensificação de relações sociais mundiais que unem localidades distantes de tal modo que os acontecimentos locais são condicionados por eventos que acontecem a muitas milhas de distância e vice-versa". Assim, por mais contraditório que o processo de globalização possa ser, ele abre espaço para possibilidades de reorganização das teias de relações sociais e econômicas em escala mundial e para o tratamento de novas questões. Estas dizem respeito à mundialização dos problemas ambientais, à instantaneidade da informação e da distribuição do conhecimento, à emergência das redes como plataforma de uma revolução sem precedentes em todas as esferas do trabalho humano, ao crescimento da importância de organizações de representação de interesses multilaterais e de organismos internacionais com funções crescentes de governo na nova ordem mundial, os quais estimulam o processo de conscientização e emergência da cidadania planetária (Greenpeace, World Wide Fund for Nature-WWFN-, etc.) (Giddens, 1991; lanni, 1996). 
O outro processo, a emergência da sociedade do conhecimento e da informação, tem como pano de fundo o progresso exponencial das novas tecnologias de informação e comunicação - TICs. Os avanços da informática revelam novas formas de organização social e que estão provocando uma verdadeira revolução social, econômica e na política. Segundo Castells (2000), a economia, a partir das duas últimas décadas do século XX, tem sua infraestrutura, de acordo com as novas tecnologias de informação e comunicação, baseada na microeletrônica, nas telecomunicações e nos programas de computador para funcionamento em rede. A flexibilidade do novo sistema tecnológico permite selecionar seus componentes, o que implica deixar de lado territórios e povos economicamente sem valor ou desvalorizados. Esse valor é indicado pelo conhecimento constante, renovado, reconfigurado pela dinâmica da sociedade de informação. Com isso, a busca constante de conhecimento tornou-se um elemento fundamental de inserção nesse mundo globalizado e condição para que se possa assumir um papel de protagonista ativo e não de mero espectador.

Neste contexto, ocorre, portanto, uma enorme revalorização do conhecimento como fonte de orientação do progresso da sociedade. É fundamental, por isso mesmo, a administração racional do conhecimento, sua geração, difusão e aplicação. A educação volta ao centro das preocupações das políticas públicas e dos projetos privados.

[...] el conocimiento es visto como el mecanismo fundamental por medio del cual la empresa, la nación o la región adquieren su capacidad de generar, procesar y aplicar eficientemente la información que se transforma en conocimiento (knowledge). Así, se desplaza la idea de que una economía sólo puede generar riqueza mediante el capital físico, ya que ahora la base de cualquier economía es el capital intangible y el capital humano en su versión contemporánea del término (GARCIA, 2003, p. 126). 
Sociologias, Porto Alegre, ano 9, no 17, jan./jun. 2007, p. 124-157

Para lidar com essas mudanças de modo a se posicionarem vantajosamente no atual contexto da globalização, os países em desenvolvimento precisam refletir sobre o projeto de desenvolvimento que querem, não apenas desenvolvimento econômico, mas especialmente o desenvolvimento humano e socialmente sustentável. É nesta orientação que a educação, de modo geral, tem um papel fundamental de fortalecimento das dimensões socioeconômicas e culturais. O conhecimento deve ser fonte de saber e não de exclusão. A distribuição do conhecimento entre os grupos sociais é um dos desafios para garantir a democracia e maior inclusão social e competitividade global.

Guadilla (2002) chama a atenção para possíveis cenários que se projetam na América Latina no novo contexto de relacionamento entre globalização, internacionalização do conhecimento e o sistema de educação superior:

a) localismo com irrelevância, quando as IES estão excluídas da globalização, tanto por auto-exclusão como crítica à mundialização ou por inabilidade de conectar-se a redes de conhecimento mundial; b) globalização com subordinação, quando as IES estão conectadas à globalização pelo consumo de conhecimento produzido externamente (clientes de software);

c) globalização com interação, quando as IES participam de maneira interativa na globalização do conhecimento, absorvendo conhecimento, de um lado, mas também produzindo conhecimentos relevantes para a sociedade. Neste cenário, é fundamental o papel comunicativo e reflexivo das instituições acadêmicas.

A autora acrescenta que a realidade certamente se aproxima a diferentes combinações desses cenários. De qualquer modo, as instituições acadêmicas devem ter o compromisso com o conhecimento socialmente relevante e o fortalecimento da sociedade civil. É muito 
Sociologias, Porto Alegre, ano 9, no 17, jan./jun. 2007, p. 124-157

importante, nesse contexto de alternativas, que os sistemas educacionais apresentem condições de sustentar um processo contínuo de incorporação de estudantes, de modo eficaz.

\section{A Expansão da Educação Superior e a Democratização do} Acesso: eqüidade, qualidade e relevância social

O desempenho do sistema educacional brasileiro: o ensino fundamental e médio

O entendimento das relações entre acesso e eqüidade na educação superior no Brasil não pode satisfazer-se com a interpretação dos números que caracterizam o processo recente de expansão desse nível de ensino entre nós. A expansão foi bastante expressiva, mas não suficiente para alterar o fato de que, na raiz do problema, persiste a realidade de uma pirâmide educacional profundamente perversa, que só permite que uma fração muito pequena de estudantes se aproxime efetivamente da educação superior. O Brasil conseguiu transformar-se numa sociedade moderna com níveis de desenvolvimento que o apresentam como potência emergente mantendo, no entanto, um desempenho extremamente precário do seu sistema educacional. Isto agora se mostra o maior empecilho a suas perspectivas futuras.

Apenas no final da década de noventa, pode-se registrar a universalização do acesso ao ensino fundamental $(96,8 \%)$, mas a taxa de escolaridade média da população continua muito baixa $-5,75$ anos entre a população branca e 4,04 anos entre a não branca -, em que pese disposição legal que torna obrigatório, pelo menos, 8 anos de escolaridade. A taxa média de anos de estudo da população em idade ativa (PIA) é mais alta, em torno de 6.52 anos de estudo (gráfico 1), mas, desdobrando-se os dados 
Sociologias, Porto Alegre, ano 9, no 17, jan./jun. 2007, p. 124-157

por região, observa-se que a região norte e nordeste ainda estão aquém deste perfil (gráfico 2). Isto significa que há altas taxas de evasão e repetência no ensino fundamental, o que implica que a taxa de matricula no ensino médio continue dramaticamente baixa.

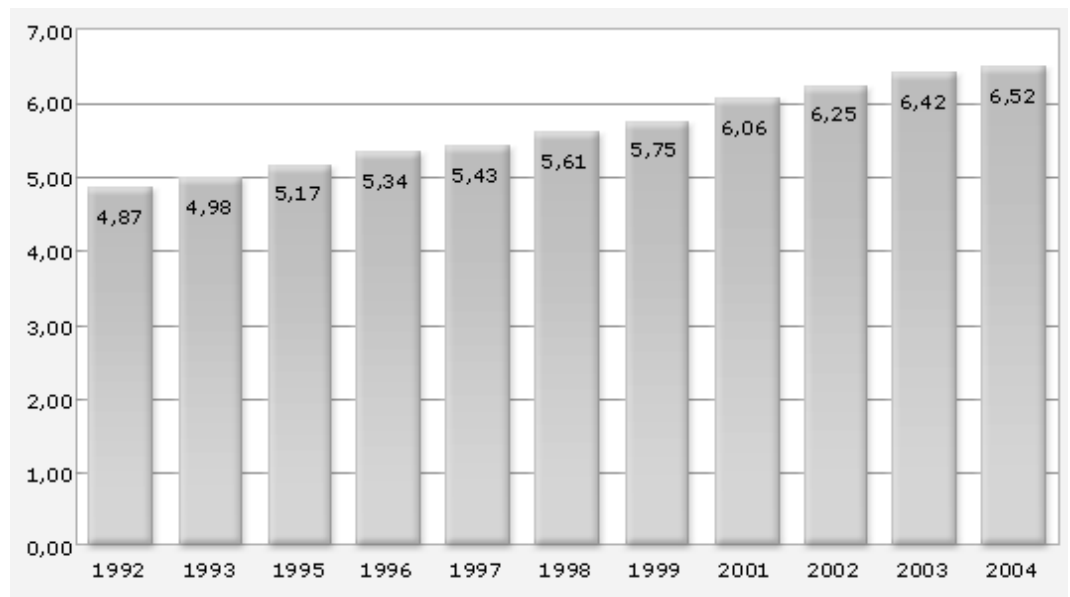

Fontes - Microdados - PNAD/IBGE. Indicadores - ASCAV/SEXEC - MCT, 2004.

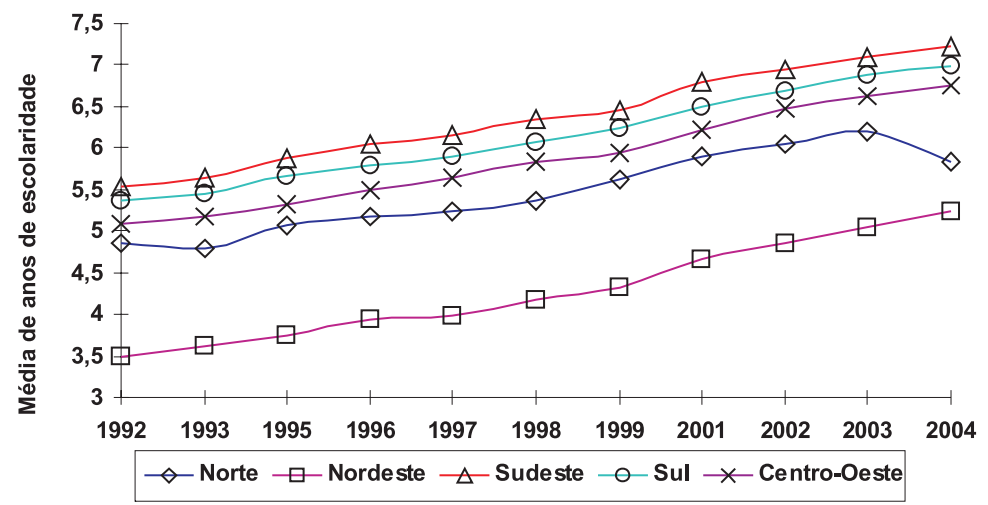

Fontes - Microdados - PNAD/IBGE. Indicadores - ASCAV/SEXEC - MCT, 2004. 
O gráfico 3 ilustra a realidade das crianças que estão fora da escola, por faixas salariais. Percebe-se que, entre 7 e 14 anos, os dados confirmam a presença na escola, ao passo que, entre 15 e 17 anos, a situação se altera, com um contingente significativo ainda fora dela (PNAD/IBGE, 2004).

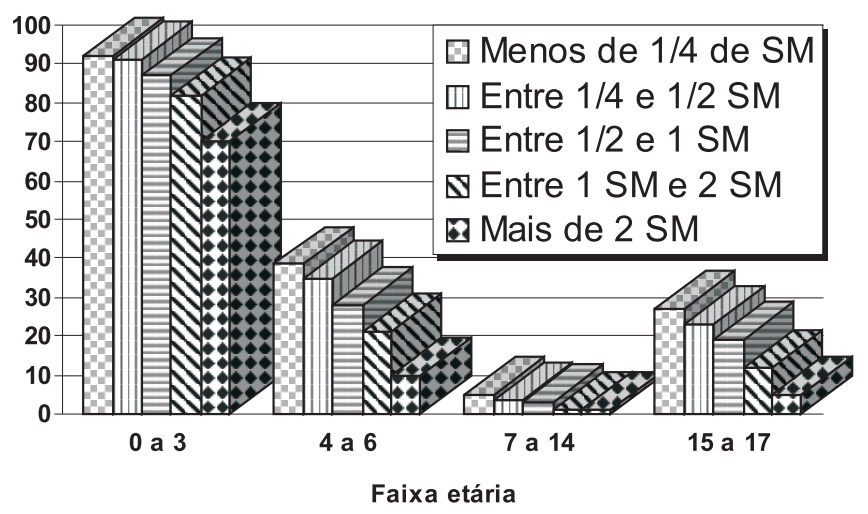

Fonte - PNAD/IBGE, 2004.

A análise dos dados sobre matrícula (tabelas 1 e 2) e conclusão (tabela 2), nos três níveis de ensino, revela que a pirâmide educacional no Brasil permanece perversa. Ou seja, há um grave problema na formação e manutenção dos alunos, já durante o ensino fundamental. 
Sociologias, Porto Alegre, ano 9, no 17, jan./jun. 2007, p. 124-157

Tabela 1 - Freqüência na creche, escola e instituições de ensino superior segundo o nível e série de ensino, e a rede freqüentada, Brasil

\begin{tabular}{|c|c|c|c|c|c|c|c|c|c|}
\hline \multicolumn{10}{|c|}{ Pessoas que freqüentavam creche ou escola } \\
\hline & \multirow{4}{*}{ Total (1) } & \multicolumn{8}{|c|}{ Grau que freqüentavam } \\
\hline & & \multirow{2}{*}{\multicolumn{2}{|c|}{ Educação Infantil }} & & Fund & lamental & & \multirow[b]{3}{*}{ Médio (4) } & \multirow[b]{3}{*}{ Superior (5) } \\
\hline & & & & \multirow[b]{2}{*}{ Total (2) } & Série & que freqüe & entavam & & \\
\hline & & Creche & Pré-escolar & & $1 \stackrel{a}{a} 4^{a}$ & 5 a a $8^{\text {a }}$ & $\begin{array}{c}\text { Sem } \\
\text { declaração (3) }\end{array}$ & & \\
\hline Total & 57.592 .749 & 1.546 .897 & 6.824 .501 & 34.277 .849 & 17.851 .021 & 15.237.228 & 403.072 & 10.130 .940 & 4.812 .562 \\
\hline \multicolumn{10}{|c|}{ Rede de ensino } \\
\hline Pública & 45.909 .238 & 882.891 & 4.946.291 & 30.569 .469 & 15.835 .012 & 13.583 .199 & 380.989 & 8.255.270 & 1.255 .317 \\
\hline Particula & r11.676.009 & 664.06 & 1.876 .727 & 3.704 .510 & 2.014.197 & 1.652 .871 & 22.083 & 1.873 .521 & 3.557 .245 \\
\hline (6) & 7502 & & 1.483 & 3.870 & 1.812 & 1.158 & & 2.149 & \\
\hline
\end{tabular}

Fonte - PNAD/IBGE, 2004. Nota: (1) Inclusive as pessoas que não declararam o curso freqüentado. (2) Inclusive os estudantes de curso de alfabetização de adultos. (3) Inclusive os estudantes que freqüentavam o supletivo não seriado. (4) Inclusive os estudantes de pré-vestibular. (5) Inclusive os estudantes de curso de mestrado e doutorado. (6) Sem declaração.

Tabela 2 - Número de matrículas e concluintes, segundo o nível de ensino, Brasil

\begin{tabular}{|c|c|c|c|c|c|c|}
\hline \multicolumn{5}{|c|}{ Matrículas } & \multicolumn{2}{|c|}{ Concluintes } \\
\hline & \multicolumn{6}{|c|}{ Nível de ensino } \\
\hline & Fundamental & Médio & Superior & Fundamental & Médio & Superior \\
\hline 1999 & 36.059 .742 & 7.769 .199 & 2.369 .945 & 2.484 .972 & 1.786 .827 & 324.734 \\
\hline 2000 & 35.717 .948 & 8.192 .948 & 2.694 .245 & 2.648 .638 & 1.836 .130 & 352.305 \\
\hline 2001 & 35.298 .089 & 8.398.008 & 3.030 .754 & 2.707 .683 & 1.855 .419 & 395.988 \\
\hline 2002 & 35.150 .362 & 8.710 .584 & 3.479 .913 & 2.778 .033 & 1.884 .874 & 466.260 \\
\hline 2003 & 34.438 .749 & 9.072 .942 & 3.887 .022 & 2.668 .605 & 1.854 .834 & 528.223 \\
\hline 2004 & 34.012 .434 & 9.169 .357 & 4.163 .733 & 2.462 .319 & 1.879 .044 & 626.617 \\
\hline 2005 & 33.534 .561 & 9.031 .302 & 4.453 .156 & $\ldots$ & $\ldots$ & 717.858 \\
\hline
\end{tabular}

Fonte - INEP/MEC, 1999-2006. 
O acesso está praticamente universalizado, mas ainda não se conseguiu que as crianças concluíssem os oito anos de escolaridade obrigatória. A taxa de conclusão no ensino fundamental é muito baixa, em torno de 2,4 milhões de alunos/ano. Aí está um dos maiores gargalos da educação brasileira. Outro dado relevante (tabela 1), aliás já conhecido, é a concentração da matrícula no ensino fundamental, de $88 \%$, e no médio de $80 \%$, na rede pública, enquanto no ensino superior a relação se inverte, com uma matrícula em torno de $70 \%$ na rede privada (PNAD/IBGE; MEC/INEP).

Segundo dados da PNAD/IBGE (2004) referentes à idade, 85\% dos alunos da 1a à 4⿳亠丷a série têm hoje entre 5 e 11 anos. O problema da permanência na escola começa na passagem da $4^{\underline{a}}$ para a $5^{\underline{a}}$ série e, da $8^{\underline{a}}$ para o ensino médio. Os alunos deveriam concluir o ensino fundamental com 14 anos, porém, apenas $66 \%$ dos alunos entre a $5^{\underline{a}}$ e $8^{\underline{a}}$ série estão nessa faixa etária. Com 15 a 17 anos são 20\%, e os demais contam mais de 18 anos. $^{2}$ De outra parte, atendendo a preocupação com a eqüidade de acesso e qualidade do e no sistema, identificam-se diferenças substantivas, senão desigualdades, entre os dados da realidade da escola pública com os indicadores da escola privada. Ou seja, as desigualdades sociais são reforçadas

2 Dentre os resultados obtidos a partir do SAEB e da Prova Brasil, destaca-se como nosso maior desafio, além de garantir a elevação geral do nível de escolarização da população, a garantia da aprendizagem. Conforme essas avaliações institucionais revelaram, em 2001, 59\% dos estudantes, que passaram no mínimo 4 anos no Ensino Fundamental, não sabiam ler. Este percentual, em 2003, caiu para 55\%. Um índice ainda absurdamente elevado. Em 2001, 52,3\% destes mesmos estudantes não resolviam operações matemáticas simples. Não houve mudança significativa em 2003, visto que este índice percentual ficou em $51,6 \%$. Neste período não chega a 5\% o percentual dos alunos que atingiram o nível adequado ou sabiam ler após este tempo percorrido no Ensino Fundamental, sendo que não chega a 7\% os que dominam as operações matemáticas simples. De outra parte, estas avaliações revelaram que os que chegam ao último ano do Ensino Fundamental, ou seja, após ter freqüentado, no mínimo, 9 anos de escola, pouco menos de 10\% lêem adequadamente, enquanto 3\% apenas dominam as competências matemáticas consideradas adequadas ao final dessa etapa escolar. Recentemente, os primeiros dados do SAEB de 2005 revelaram o menor índice de desempenho em português e matemática dos alunos de nível fundamental (4⿳亠口冖 e $8^{\underline{o}}$ séries) e ensino médio ( $3^{\circ}$ ano), registrado nos últimos 10 anos. 
Sociologias, Porto Alegre, ano 9, no 17, jan./jun. 2007, p. 124-157

pelas desigualdades de desempenho escolar. Esta realidade vai desaguar no perfil do aluno de ensino superior, como se verá mais adiante, majoritariamente oriundo de famílias de condição socioeconômica mais elevada.

A questão crucial é entender o número ainda baixo de jovens que concluem o ensino fundamental a cada ano. Registra-se um leve acréscimo no número de concluintes nesse nível até 2002, quando ele volta a decrescer (tabela 2).

Também o nível médio, apesar do crescimento constante da matrícula nos últimos anos, apresenta uma taxa de matrícula muito baixa. Apenas $47 \%$ dos jovens entre 15 a 17 anos cursam esse nível, 35\% dos matriculados têm 18 a 24 anos e os demais, 25 anos ou mais de idade (PNAD/IBGE, 2004). Tomando-se uma média da matrícula por anos do nível médio (três anos), a expectativa de concluintes não é alcançada, novamente é baixa, em torno de 1,8 milhões de alunos apenas, por ano. Esses dados são reveladores da pirâmide educacional brasileira (figura 1), que apresenta a porcentagem de pessoas estudando segundo a faixa etária e o sexo.

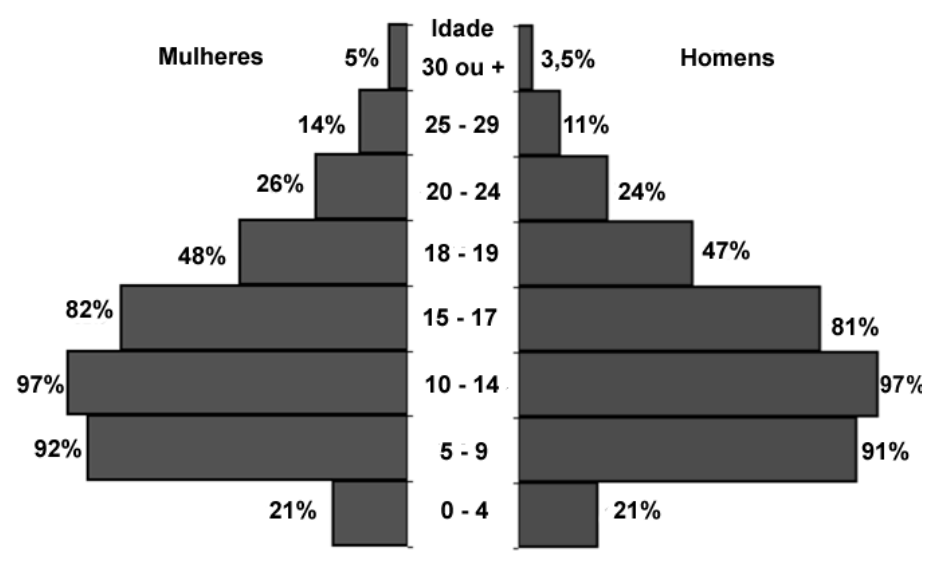

Fonte - PNAD/IBGE, 2005. 
Sociologias, Porto Alegre, ano 9, no 17, jan./jun. 2007, p. 124-157

Essa situação necessitaria uma análise à parte, para compreender as razões deste atraso educacional. Poder-se-ia apontar a falta de políticas sociais e/ou de recursos? Cabe observar, no entanto, que dados de 2002 revelam que o gasto público em educação no Brasil não é baixo ( $4,1 \%)$, em comparação com o dos países europeus (Portugal, 5,9\%; França, 5,6\%; Espanha, 4,5\%) e latino-americanos (México, 5,3\%; Chile, 4,1\%; Argentina, $4,0 \%$, etc) (OECD, INEP/MEC, 2004). No entanto, tal comparação deve considerar o histórico de investimentos e qualidade educacional, senão de capital cultural, pertinente a cada formação social. Deste modo, considerando a dívida social e educacional para com o conjunto de nossa população, poder-se-á concluir que tais investimentos não passam de pífios. Do total investido, 19\% dos recursos vão para o ensino superior, 49\% para o ensino fundamental, $13 \%$ para o nível médio, $11 \%$ para o EJA e $8 \%$ para a educação infantil.

Nos últimos anos também já foram implementadas uma série de políticas sociais, com vistas a garantir a permanência das crianças na escola, como mostra o quadro.

Das políticas executadas cabe destacar, especialmente, o Fundo de Manutenção e Desenvolvimento do Ensino Fundamental e de Valorização do Magistério (FUNDEF), o qual foi instituído pela Emenda Constitucional no14, de setembro de 1996, e regulamentado pela Lei no 9.424, de 24 de dezembro do mesmo ano, e pelo Decreto no 2.264, de junho de 1997. O FUNDEF foi implantado, nacionalmente, em 1 o de janeiro de 1998, ocasião em que passou a vigorar a nova sistemática de redistribuição dos recursos destinados ao ensino fundamental. Atualmente o FUNDEF foi substituído pelo FUNDEB, com a inclusão do nível médio e educação infantil, já foi aprovado na Câmara e no Senado, aguardando sua promulgação e regulamentação por parte da Presidência da Republica. 
Sociologias, Porto Alegre, ano 9, no 17, jan./jun. 2007, p. 124-157

\begin{tabular}{|c|c|c|}
\hline $\begin{array}{l}\text { Projeto } \\
\text { Merenda } \\
\text { Escolar }\end{array}$ & $\begin{array}{c}\text { Objetivo } \\
\begin{array}{c}\text { Ajudar Estados e municípios a oferecer merenda escolar } \\
\text { na educação infantil e no ensino fundamental }\end{array}\end{array}$ & $\begin{array}{l}\text { Quanto repassa } \\
\text { R\$0,18 por dia por } \\
\text { aluno }^{1}\end{array}$ \\
\hline $\begin{array}{l}\text { Educação de Jovens } \\
\text { e Adultos(EJA) }\end{array}$ & $\begin{array}{l}\text { Complementar recursos para a educação de jovens e } \\
\text { adultos de primeira a oitava séries de ensino fundamental }\end{array}$ & $\begin{array}{l}\mathrm{R} \$ 250,00 \text { por aluno } \\
\text { no ano de } 2003\end{array}$ \\
\hline $\begin{array}{l}\text { Biblioteca da } \\
\text { escola }\end{array}$ & $\begin{array}{l}\text { Estimular a leitura e dotar as escolas públicas de um } \\
\text { acervo mínimo de livros }\end{array}$ & $\begin{array}{l}\text { Receberam o acervo } \\
\text { as escolas de } 1^{\mathrm{a}} \text { a } 4^{\mathrm{a}} \\
\text { série do ensino } \\
\text { fundamental (mais de } \\
150 \text { livros cada no } \\
\text { censo de 1999) }\end{array}$ \\
\hline $\begin{array}{l}\text { Livro } \\
\text { didático }\end{array}$ & $\begin{array}{l}\text { Garantir que todos os alunos de escolas públicas de } \\
\text { ensino fundamental tenham livro didático para estudar }\end{array}$ & $\begin{array}{l}\text { Não há um valor fixo. O } \\
\text { MEC centraliza a compra } \\
\text { e repassa a escolas e } \\
\text { secretarias conforme o } \\
\text { número de alunos }\end{array}$ \\
\hline $\begin{array}{l}\text { Dinheiro direto } \\
\text { na escola }\end{array}$ & $\begin{array}{l}\text { Repassar diretamente recursos para a escola, } \\
\text { aumentando sua autonomia e diminuindo burocracia }\end{array}$ & $\begin{array}{l}\text { Dependendo do } \\
\text { número de alunos na } \\
\text { escola e da região, ela } \\
\text { pode receber entre } R \$ \\
600,00 \text { e } R \$ 19.000,00\end{array}$ \\
\hline $\begin{array}{c}\text { Bolsa Escola } \\
\text { (substituído por } \\
\text { Bolsa Família/2003) }\end{array}$ & $\begin{array}{c}\text { Repasse recursos para famílias, de jovens entre } 6 \text { e } 15 \\
\text { anos que freqüentam escola, com renda per capita } \\
\text { inferior a } \operatorname{R} \$ 90,00 .\end{array}$ & $\begin{array}{l}\mathrm{R} \$ 15,00 \text { mês } \\
\text { por aluno }\end{array}$ \\
\hline $\begin{array}{l}\text { FUNDEF } \\
(1996-2006)\end{array}$ & $\begin{array}{c}\text { Redistribuir recursos entre Estados, União e municípios } \\
\text { para garantir que seja realizado um gasto mínimo por } \\
\text { aluno em todo o Brasil. }\end{array}$ & $\begin{array}{l}\mathrm{R} \$ 537,71 \text { por ano por } \\
\text { aluno de } 1^{\mathrm{a}} \text { a } 4^{\mathrm{a}} \text { série e } \\
\mathrm{R} \$ 564,60 \text { por ano por } \\
\text { aluno de } 5^{\mathrm{a}} \text { a } 8^{\mathrm{a}} \text { série*. A } \\
\text { previsão para } 2006 \text { era } \\
\text { de um investimento total } \\
\text { de: } \mathrm{R} \$ 35,5 \text { bilhões. }\end{array}$ \\
\hline $\begin{array}{l}\text { FUNDEB } \\
(2007-)\end{array}$ & $\begin{array}{l}\text { Ampliação dos recursos do FUNDEF e extensão do } \\
\text { atendimento à educação infantil e média, objetivando } \\
\text { atender a faixa etária de } 0-5 \text {, e } 15-17 \text { anos que, ao } \\
\text { contrário do ensino fundamental, ainda apresenta baixas } \\
\text { taxas de acesso e freqüência }\end{array}$ & $\begin{array}{c}\text { A previsão para o } \\
\text { primeiro ano de } \\
\text { vigência é de: } \mathrm{R} \$ 43,1 \\
\text { bilhões, esperando-se } \\
\text { alcançar, no terceiro } \\
\text { ano, R\$ 55,2 bilhões }\end{array}$ \\
\hline
\end{tabular}

1 Em 2006, o valor per capita de uma parte dos alunos recebeu novo aumento, passando para $\mathrm{R} \$ 0,22$ por dia para os alunos de creches públicas e filantrópicas, e para $\mathrm{R}$ \$ 0,42 para os alunos de escolas indígenas e remanescentes de quilombos. Para os alunos do ensino fundamental e da pré-escola, o valor permanece de R \$ 0,18 por aluno/dia. (MEC, 2006).

Fonte - INEP/MEC. Nota: *Quando os Estados e Municípios não conseguem atingir com arrecadação própria esse valor, a União transfere recursos para complementar. Fonte: www.mec.gov.br /2004. 
Sociologias, Porto Alegre, ano 9, no 17, jan./jun. 2007, p. 124-157

A maior inovação do FUNDEF consistiu na mudança da estrutura de financiamento do ensino fundamental no País ( $1 \underline{\underline{a}}$ a $8^{2}$ séries), ao subvincularIhe uma parcela dos recursos constitucionalmente destinados à educação. A Constituição de 1988 vincula $25 \%$ das receitas dos estados e dos municípios à educação. Com a Emenda Constitucional no 14/96, 60\% desses recursos (o que representa $15 \%$ da arrecadação global de estados e municípios) passaram a ser reservados ao ensino fundamental.

O FUNDEF representou uma autêntica revolução no atendimento ao ensino fundamental nas redes públicas do País, em especial em face do seu critério redistributivo de recursos. Esse seu modelo tornou possível direcionar os recursos reservados à Educação para onde estavam, de fato, os alunos. A partir da instituição desse Fundo, foram movimentados recursos dos governos com maior capacidade financeira e/ou com um baixo nível de participação no atendimento escolar, para os municípios em situação inversa. Já no primeiro ano de funcionamento do FUNDEF (1998), 2.703 Municípios obtiveram ganhos financeiros, em um processo crescente de redistribuição. Em 2001, 3.404 Municípios foram beneficiados, por meio de obtenção de uma receita adicional de $\mathrm{R} \$ 2,9$ bilhões.

A reserva de $60 \%$ dos recursos do Fundo para a remuneração do magistério representou aumentos importantes nos salários dos professores em efetivo exercício da docência no ensino fundamental. Entre dezembro de 1997 e junho de 2000, o aumento médio na remuneração dos professores foi de $29,6 \%$, com destaque para algumas regiões, como o Nordeste, onde os docentes do Ensino Fundamental foram beneficiados com um aumento médio de 59,6\%, aí incluídas as redes municipais e estaduais. Com o crescimento de suas receitas, os Municípios nordestinos destacaram-se no aumento concedido aos professores, o qual atingiu uma média de $70,2 \%$, no mesmo período. 
Sociologias, Porto Alegre, ano 9, no 17, jan./jun. 2007, p. 124-157

No final de 2003, foi criado o programa Bolsa Família por decisão governamental, unificando diferentes programas federais de transferência de recursos, entre eles Bolsa Escola, em um programa diretamente vinculado à Presidência da República, sob a direção de um Conselho interministerial especial. O novo Programa deveria conceder uma renda mínima de $\mathrm{R} \$$ 50,00 por mês para cada família com renda per capita mensal de $\mathrm{R} \$ 50,00$ ou menos, com benefícios adicionais para mulheres grávidas, crianças pequenas, crianças na escola, subsídios para alimentação e gás, que antes faziam parte de programas separados (Brasil, Presidência da República, 2004).

Recentemente, a Emenda Constitucional № 53 (aprovada em 06 de dezembro de 2006) criou o Fundeb - Fundo de Manutenção e Desenvolvimento da Educação Básica e de Valorização dos Profissionais da Educação que tem por objetivo proporcionar a elevação das taxas de atendimento, principalmente na educação média e infantil, e um considerável aumento e nova distribuição dos investimentos em educação.

Por que, mesmo com os recursos que o Brasil investe na educação e com as políticas sociais voltadas para a inclusão social, o desempenho educacional continua tão baixo? De um lado, poder-se-ia afirmar que o Brasil gasta mal e não há controle do gasto; por outro, talvez se faça necessário um maior incremento ainda de recursos para reverter a situação, especialmente no que se refere a salário e formação dos professores.

Compreendida esta realidade básica e tendo em vista que a razão principal da iniqüidade do acesso ao ensino superior continua sendo o insucesso dos níveis anteriores de ensino com relação à inclusão social, é possível estabelecer condições melhores de abordagem e compreensão do que se tem passado com a educação superior no país. 
Sociologias, Porto Alegre, ano 9, no 17, jan./jun. 2007, p. 124-157

Acesso e eqüidade na educação superior

A educação superior mostra uma evolução compatível com a realidade da educação básica, quando atende apenas 10,6\% da população entre 18 e 24 anos. As tabelas abaixo revelam dois aspectos importantes do processo de exclusão, considerando o total de jovens da faixa etária: a saída precoce do sistema educacional, quando de fato, $68 \%$ dos jovens não estudam mais e o atraso escolar quando se relaciona série/idade, ou seja, $6,25 \%$ dos jovens da faixa etária, ainda cursam o fundamental e 15\%, o nível médio (tabelas 3 e 4).

Tabela 3 - Jovens de 18 a 24 anos, não estudantes, estudantes, e estudantes distribuídos segundo nível de ensino freqüentado, Brasil

\begin{tabular}{ccccccc}
\hline & Total (1) & Não estudantes & Estudantes (2) & Fundamental & Médio (3) & Superior (4) \\
\hline $\begin{array}{c}\text { Jovens de 18 a } \\
\text { 24 anos }\end{array}$ & 24.072 .318 & 16.327 .459 & 7.744 .859 & 1.504 .012 & 3.683 .112 & 2.557 .735 \\
\hline $\begin{array}{c}\text { Porcentagem } \\
(\%)\end{array}$ & 100 & 67,83 & 32,17 & 6,25 & 15,3 & 10,63 \\
\hline
\end{tabular}

Fonte - PNAD/IBGE, 2004. Nota: (1) Inclusive as pessoas que não declararam o curso freqüentado. (2) Inclusive os estudantes de cursos de alfabetização de adultos. (3) Inclusive os estudantes de pré-vestibular. (4) Inclusive os estudantes de curso de mestrado e doutorado.

Tabela 4 - Estudantes de 18 a 24 anos segundo o nível de ensino que freqüentam, Brasil

\begin{tabular}{ccccc}
\hline & Total (1) & Fundamental (1) & Médio (3) & Superior (4) \\
\hline $\begin{array}{c}\text { Estudantes de } \\
18 \text { a 24 anos }\end{array}$ & 7.744 .859 & 1.504 .012 & 3.683 .112 & 2.557 .735 \\
\hline $\begin{array}{c}\text { Porcentagem } \\
(\%)\end{array}$ & 100 & 19,42 & 47,56 & 33,02 \\
\hline
\end{tabular}

Fonte - PNAD/IBGE, 2004. Nota: (1) Inclusive os estudantes de cursos de alfabetização de adultos. (2) Inclusive os estudantes de pré-vestibular. (3) Inclusive os estudantes de curso de mestrado e doutorado. 
Sociologias, Porto Alegre, ano 9, no 17, jan./jun. 2007, p. 124-157

A tabela 5 detalha os dados, ainda que de 2003, por região, confirmando os índices mais positivos para as regiões sudeste e sul.

Tabela 5 - Estudantes de 18 a 24 anos de idade, total e sua respectiva distribuição segundo os níveis de ensino, Brasil e Grandes Regiões, 2003.

\begin{tabular}{c|c|c|c|c|c}
\hline & \multicolumn{5}{|c}{ Estudantes de 18 a 24 anos de idade } \\
\cline { 2 - 6 } & & \multicolumn{3}{|c}{ Nível de ensino freqüentado (\%) } \\
\cline { 2 - 6 } Grandes Regiões & Total (1) & $\begin{array}{c}\text { Fundamental } \\
\text { ou 1o grau }\end{array}$ & $\begin{array}{c}\text { Médio ou } \\
2 \text { o grau }\end{array}$ & $\begin{array}{c}\text { Pré- } \\
\text { vestibular }\end{array}$ & $\begin{array}{c}\text { Superior ou } \\
\text { 3o grau (2) }\end{array}$ \\
\hline Brasil (3) & 7.945 .747 & 20,4 & 41,8 & 5,3 & 31,7 \\
\hline Norte (4) & 578.913 & 27,2 & 49,7 & 5,6 & 16,7 \\
Nordeste & 2.583 .518 & 33,9 & 44,2 & 4,8 & 15,4 \\
Sudeste (1) & 3.148 .700 & 12,5 & 40,5 & 5,7 & 41,0 \\
Sul (1) & 1.072 .104 & 9,2 & 36,1 & 5,4 & 48,6 \\
Centro-Oeste & 552.379 & 16,1 & 41,3 & 3,9 & 38,1 \\
\hline
\end{tabular}

Nota - (1) Inclusive a população que freqüentava cursos de alfabetização de adultos. (2) Inclui graduação, mestrado e doutorado. (3) Exclusive a população rural de Rondônia, Acre, Amazonas, Roraima, Pará e Amapá. (4) Exclusive a população rural.

A questão básica a ser enfrentada é a seguinte: o que ajuda a explicar tal desempenho do sistema educacional brasileiro, em particular da educação superior, que ainda hoje mostra taxas líquidas de matricula muito inferiores às de países com nível de desenvolvimento bem menor, como os seus vizinhos da América do Sul (ver tabela 6).

Tomada em conjunto, a expansão da educação superior no Brasil, em que pesem os números elevados, revela um quadro problemático, seja quando comparada à dimensão da população na faixa etária que, poderia esperar-se, pudesse estar a se dirigir para aquele nível de ensino, seja em termos comparativos com outros países em mesmo estágio de desenvolvimento ou menor. A taxa líquida de matrícula na educação superior mantém-se muito baixa no Brasil e uma das mais baixas em nível internacional. O mesmo acontece com a taxa bruta, como mostra a tabela 7. 
Sociologias, Porto Alegre, ano 9, no 17, jan./jun. 2007, p. 124-157

Tabela 6 - Taxa bruta de acesso (\%) ao ensino superior por países selecionados da América Latina, 1975-2003.

\begin{tabular}{ccccccc}
\hline País & 1975 & 1980 & 1985 & 1990 & 1995 & 2003 \\
\hline Argentina & 26 & 22,2 & 36,4 & 38,8 & 37,3 & 59,8 \\
Bolivia & 12 & 12,8 & 18,7 & 19 & 23,2 & 39,4 \\
Brasil & 10,8 & 12 & 10 & 11 & 11,9 & 20 \\
Chile & 15,7 & 10,8 & 9,1 & 19,8 & 28,1 & 42,4 \\
Colombia & 8,2 & 10,2 & 12,6 & 14 & 18,1 & 24,3 \\
Guyana & 3,8 & 2,6 & 2,1 & $\ldots$ & $\ldots$ & 6,1 \\
Paraguay & 6,9 & 8,8 & 8,5 & 7,6 & 8,1 & 27 \\
Peru & 14,6 & 19,8 & 24,4 & 26,6 & 29,6 & 31,9 \\
Uruguay & 16 & 16,4 & 33,8 & 30,1 & 31,4 & 37,4 \\
Venezuela & 18,7 & 21,4 & 25,7 & 29,6 & 36,4 & 40,2 \\
\hline
\end{tabular}

Fonte - IESALC/UNESCO; BADEINSO/CEPAL.

Tabela 7 - Número bruto e taxa de acesso à educação superior da população entre 18 e 24 anos de idade, segundo países selecionados, 2004

\begin{tabular}{c|c|c|c}
\hline País & $\begin{array}{c}\text { População de } \\
\text { 18 a 24 anos }\end{array}$ & $\begin{array}{c}\text { Matrículas } \\
18-24 \text { anos }\end{array}$ & $\begin{array}{c}\% \text { Acesso } \\
18-24 \text { anos }\end{array}$ \\
\hline Alemanha & 3.408 .515 & 1.111 .394 & 32,6 \\
Argentina & 2.237 .796 & 1.187 .416 & 53,1 \\
Austrália & 978.402 & 547.194 & 55,9 \\
Bélgica $^{4}$ & 449.567 & 293.995 & 65,4 \\
Brasil $^{*}$ & $\mathbf{2 4 . 0 7 2 . 3 1 8}$ & $\mathbf{2 . 5 5 7 . 7 3 5}$ & $\mathbf{1 0 , 6}$ \\
Coréia do Sul $^{2.804 .888}$ & 2.619 .480 & 93,4 \\
Estados Unidos $^{14.707 .893}$ & 9.564 .801 & 65,0 \\
Itália & 2.289 .217 & 1.163 .524 & 50,8 \\
México & 7.128 .556 & 1.770 .951 & 24,8 \\
Reino Unido & 2.575 .352 & 1.185 .345 & 46,0 \\
Suíça & 303.469 & 90.665 & 29,9 \\
\hline
\end{tabular}

Fonte - OECDE. Nota: * dados da PNAD/IBGE/2004. 
Sociologias, Porto Alegre, ano 9, no 17, jan./jun. 2007, p. 124-157

A educação superior no Brasil apresentava-se, até muito recentemente, como um domínio reservado aos jovens provenientes das camadas mais ricas da população. Após uma onda de crescimento nos anos 1970, a matrícula manteve-se inalterada até meados dos anos noventa. Ao longo dos governos militares (1964-1985), as políticas oficiais contiveram a expansão do ensino de graduação público e gratuito e permitiram a multiplicação dos estabelecimentos privados onde o ensino era pago. Mesmo assim, havia um razoável equilíbrio na distribuição da matrícula entre as IES públicas e as privadas. A desigualdade mostrava-se na qualidade. Com exceção de umas poucas universidades católicas, em particular a PUC do Rio de Janeiro, as instituições privadas eram de baixa qualidade. As instituições públicas gratuitas paradoxalmente recebiam os jovens de famílias de classe mais elevada que haviam realizado seus estudos secundários em escolas privadas e pagas, de boa qualidade. Ou seja, as camadas de renda mais alta pagavam as melhores escolas de nível médio e asseguravam, assim, para seus filhos maiores chances de admissão nas universidades públicas e gratuitas.

Hoje, no entanto, cresce cada vez mais, a percepção de que a educação e, em particular a educação superior, começa a se constituir num ponto de estrangulamento das chances de um vigoroso processo de desenvolvimento nacional que poderia assegurar papel internacional de destaque ao País.

O tema da democratização do acesso à educação superior de qualidade reveste-se, assim, de grande importância. A experiência que o Brasil vem vivendo com relação às transformações no âmbito da educação superior é muito rica e serve como importante referência para análise dos desafios da educação superior na sociedade contemporânea e, em particular, nos países emergentes.

A questão do acesso e da eqüidade na educação superior deve ser, pois, discutida e analisada tendo por referência três aspectos básicos: a) o processo de expansão do ensino superior tem assegurado maior acesso à educação superior de qualidade? b) em que medida a diferenciação da oferta de oportunidades de educação pós-secundária e superior podem 
Sociologias, Porto Alegre, ano 9, no 17, jan./jun. 2007, p. 124-157

facilitar a democratização do acesso? c) como e em que extensão as políticas afirmativas e de inclusão social estimulam a democratização do acesso.

Expansão

A ampliação da procura por educação superior é uma das tendências centrais na sociedade contemporânea. Entre os fatores que têm contribuído para este processo destacam-se a valorização do conhecimento científiCo, a defesa dos direitos sociais (mais educação), a aspiração das famílias por mobilidade social através da educação, a necessidade de aquisição de mais competências para enfrentar o mercado de trabalho, etc.

No Brasil, em 1995, a matrícula na educação superior alcançava pouco mais de 1,5 milhões de estudantes. Dez anos depois, ela ultrapassou a marca dos 3 milhões de matrículas conforme a tabela 8. Hoje contam-se mais de 4 milhões de estudantes. Esse crescimento, em parte, foi resultado da expansão do ensino médio, embora em 2002 apenas 40\% dos jovens entre 15 e 17 anos estivessem cursando esse nível, aumentando, em 2004, para 47\%. No entanto, em 2005 a expansão atingiu apenas cerca de 11,5\% dos jovens entre 18 e 24 anos, uma das taxas mais baixas da América Latina.

Do total das matrículas, em 2002, 58\% eram mulheres, $76 \%$ brancos, $41 \%$ correspondiam aos $10 \%$ do segmento mais rico, e 7,5\% dos $50 \%$ dos mais pobres (PNAD/IBGE,2003). A expansão se processou pela rede privada, que detém mais de $70 \%$ das matrículas em cursos de graduação.

A tabela 8 e 9 mostram o crescimento da matrícula por instituição mantenedora, pública e privada (ver também o Gráfico 4). O que chama atenção é que, sem dúvida, registra-se uma expansão quantitativa significativa, quando a matrícula praticamente duplica em cinco anos. No entanto, ao detalhar o processo de expansão, observa-se que na rede pública houve um aumento de 217.000 mil vagas, ao passo que a rede privada ofereceu 1.7 millhões de vagas a mais, neste período. 
Tabela 8 - Distribuição percentual e taxa de crescimento da matrícula em cursos de graduação presenciais, segundo a categoria administrativa.

\begin{tabular}{|c|c|c|c|c|c|c|c|c|c|c|c|c|c|c|c|}
\hline \multicolumn{16}{|c|}{ Numero de matrículas em cursos de graduação } \\
\hline \multirow[b]{2}{*}{ Ano } & \multirow[b]{2}{*}{ Brasil } & \multicolumn{8}{|c|}{ Pública } & \multicolumn{6}{|c|}{ Privada } \\
\hline & & Total & $\%$ & Federal & $\%$ & Estadual & $\%$ & Municipal & $\%$ & Total & $\%$ & Particular & $\%$ & \begin{tabular}{|c|}
$\begin{array}{c}\text { Comunit// } \\
\text { Conf/Fila } \\
\mathrm{nt}^{*}\end{array}$ \\
\end{tabular} & $\%$ \\
\hline 1991 & 1.565 .056 & 605.736 & 38,7 & 320.135 & 52,9 & 202.315 & 33,4 & 83.286 & 13,7 & 959.320 & 61,3 & 959.320 & 100,0 & 0 & 0,0 \\
\hline 1992 & 1.535 .788 & 629.662 & 41,0 & 325.884 & 51,8 & 210.133 & 33,4 & 93.645 & 14,9 & 906.126 & 59,0 & 906.126 & 100,0 & 0 & 0,0 \\
\hline 1993 & 1.594 .668 & 653.516 & 41,0 & 344.387 & 52,7 & 216.535 & 33,1 & 92.594 & 14,2 & 941.152 & 59,0 & 941.152 & 100,0 & 0 & 0,0 \\
\hline 1994 & 1.661 .034 & 690.450 & 41,6 & 363.543 & 52,7 & 231.936 & 33,6 & 94.971 & 13,8 & 970.584 & 58,4 & 970.584 & 100,0 & 0 & 0,0 \\
\hline 1995 & 1.759 .703 & 700.540 & 39,8 & 367.531 & 52,5 & 239.215 & 34,1 & 93.794 & 13,4 & 1.059 .163 & 60,2 & 1.059 .163 & 100,0 & 0 & 0,0 \\
\hline 1996 & 1.868 .529 & 735.427 & 39,4 & 388.987 & 52,9 & 243.101 & 33,1 & 103.339 & 14,1 & 1.133 .102 & 60,6 & 1.133 .102 & 100,0 & 0 & 0,0 \\
\hline 1997 & 1.945 .615 & 759.182 & 39,0 & 395.833 & 52,1 & 253.678 & 33,4 & 109.671 & 14,4 & 1.186 .433 & 61,0 & 1.186 .433 & 100,0 & 0 & 0,0 \\
\hline 1998 & 2.125 .958 & 804.729 & 37,9 & 408.640 & 50,8 & 274.934 & 34,2 & 121.155 & 15,1 & 1.321.229 & 62,1 & 1.321.229 & 100,0 & 0 & 0,0 \\
\hline 1999 & 2.369 .945 & 832.022 & 35,1 & 442.562 & 53,2 & 302.380 & 36,3 & 87.080 & 10,5 & 1.537 .923 & 64,9 & 651.362 & 42,4 & 886.561 & 57,6 \\
\hline 2000 & 2.694 .245 & 887.026 & 32,9 & 482.750 & 54,4 & 332.104 & 37,4 & 72.172 & 8,1 & 1.807 .219 & 67,1 & 880.555 & 48,7 & 926.664 & 51,3 \\
\hline 2001 & 3.030 .754 & 939.225 & 31,0 & 502.960 & 53,6 & 357.015 & 38,0 & 79.250 & 8,4 & 2.091 .529 & 69,0 & 1.040 .474 & 49,7 & 1.051 .055 & 50,3 \\
\hline 2002 & 3.479 .913 & 1.051 .655 & 30,2 & 531.634 & 50,6 & 415.569 & 39,5 & 104.452 & 9,9 & 2.428.258 & 69,8 & 1.261 .901 & 52,0 & 1.166 .357 & 48,0 \\
\hline 2003 & 3.887 .022 & 1.136 .370 & 29,2 & 567.101 & 49,9 & 442.706 & 39,0 & 126.563 & 11,1 & 2.750 .652 & 70,8 & 1.475 .094 & 53,6 & 1.275 .558 & 46,4 \\
\hline 2004 & 4.163 .733 & 1.178 .328 & 28,3 & 574.584 & 48,8 & 471.661 & 40,0 & 132.083 & 11,2 & 2.985 .405 & 51,7 & 1.596 .894 & 53,5 & 1.388 .511 & 46,5 \\
\hline
\end{tabular}

Fonte - INEP/MEC.

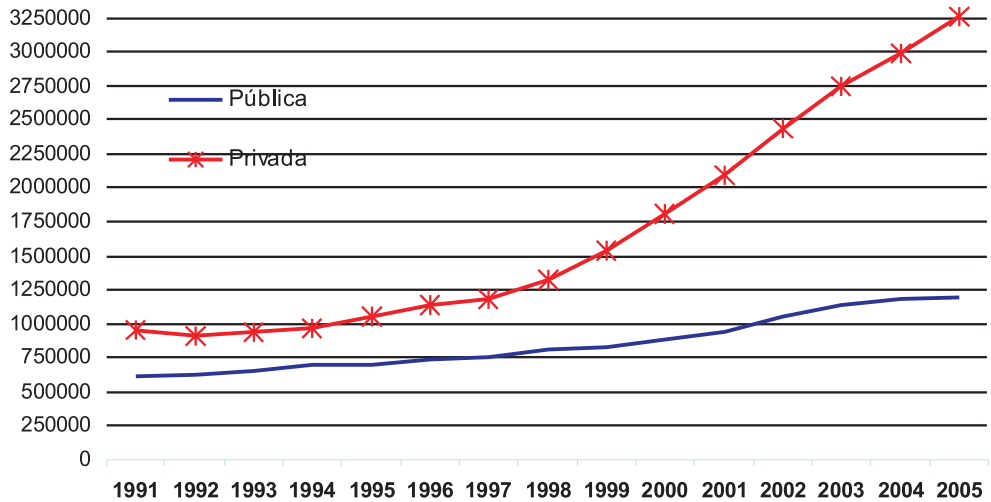

Fontes - Inep /MEC; Indicadores - ASCAV/SEXEC - MCT. 
Tabela 9 - Vagas, inscrições, ingressantes pelo vestibular e matrículas e concluintes do ensino superior, segundo a dependência administrativa ,19802005.

\begin{tabular}{|c|c|c|c|c|c|c|c|c|c|c|}
\hline & 1980 & 1985 & 1990 & 1995 & 2000 & 2001 & 2002 & 2003 & 2004 & 2005 \\
\hline \multicolumn{11}{|l|}{ Brasil } \\
\hline Vaga & 14 & & & & & & & & & 37 \\
\hline Inscrições & 1.80 & 1.514.341 & 1.905 .498 & 2.653 & & & & & 92 & 20 \\
\hline Ingressantes & 356.667 & 346.380 & 407.148 & 510.377 & 897.557 & & 1.205 & 1.2 & 1.303 .110 & 1.394 .066 \\
\hline Matrículas & 1.377 .286 & 1.36 & 1.54 & 1.759 & 2.694 .245 & 3.0 & 3.479 & 3.887 & 33 & 4.4 \\
\hline Concluintes & 226.423 & 234.173 & 230.271 & 254.401 & 352.307 & 395. & 466.260 & 528.102 & 626.597 & 717.858 \\
\hline \multicolumn{11}{|l|}{ Público } \\
\hline Vaga & & & & 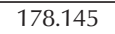 & 275 & & & & & \\
\hline scrições & & 37 & 51 & 1.399 .092 & 2.178 .918 & 2.22 & 2.627 .200 & 2.36 & 2.43 & 2.28 \\
\hline Ingressantes & 117.414 & 123.744 & 126.139 & 158.012 & 233.083 & 244. & 280.491 & 267.031 & 287.242 & 287.591 \\
\hline Matrículas & 492.232 & 556.680 & 578.625 & 700.540 & 887.026 & 939.225 & 1.051 .655 & 1.137 .119 & 1.178 .328 & 1.192 .189 \\
\hline Concluintes & 80.948 & 82.444 & 77.919 & 94.951 & 116.641 & 132.616 & 151.101 & 169.038 & 202.262 & 195.554 \\
\hline \multicolumn{11}{|l|}{ Privado } \\
\hline & & & & & & & & & & \\
\hline crições & 3 & 34.454 & 1.023 .937 & 1.254 .761 & 1.860 & 2. & 2.3 & & 2.6 & 511 \\
\hline Ingressantes & 239.253 & 222.636 & 281.009 & 352.365 & 664.474 & 792.069 & 924.649 & 995.873 & 1.015 .868 & 1.106 .475 \\
\hline Matrículas & 885.054 & 10.929 & 961.455 & 1.059 .163 & 1.807 .219 & 2.091 .529 & 2.428 .258 & 2.750 .652 & 2.985 .405 & 3.260 .967 \\
\hline Concluintes & 145.475 & 151.729 & 152.352 & 159.450 & 235.664 & 263.372 & 315.159 & 359.064 & 424.335 & 522.304 \\
\hline
\end{tabular}

Fonte - INEP/MEC.

Analisando-se os dados da demanda por educação superior, pode-se deduzir que os inscritos para o vestibular representam um público muito diferenciado, chegando a 4,9 milhões de inscritos. O que chama atenção na tabela 9 é a diferença entre o número de ingressantes e o número de vagas oferecidas, praticamente em todos os anos. Apenas 63\% das vagas oferecidas no Brasil são preenchidas. No setor público são 95\%, enquanto no setor privado, o número de vagas preenchidas é de 57,8\% (ver Gráfico 5).

Uma outra questão a ser analisada refere-se ao movimento de ampliação real de abertura de oportunidades para estudantes oriundos de segmentos socioeconômicos inferiores. Os dados relativos à expansão da matrícula no nível superior, ao contrário do que se poderia supor, revelam que essa expansão não trouxe mudanças significativas na composição social dos estudantes. Uma das razões, como já se mostrou, é a baixa taxa de estudantes vindos do ensino médio; a outra é o baixo crescimento de vagas nas 
Sociologias, Porto Alegre, ano 9, no 17, jan./jun. 2007, p. 124-157

instituições públicas. Os dados mostram que não há diferença significativa tomando-se como indicador a renda familiar dos alunos, entre os matriculados no ensino superior público e privado, como indica a tabela 10.

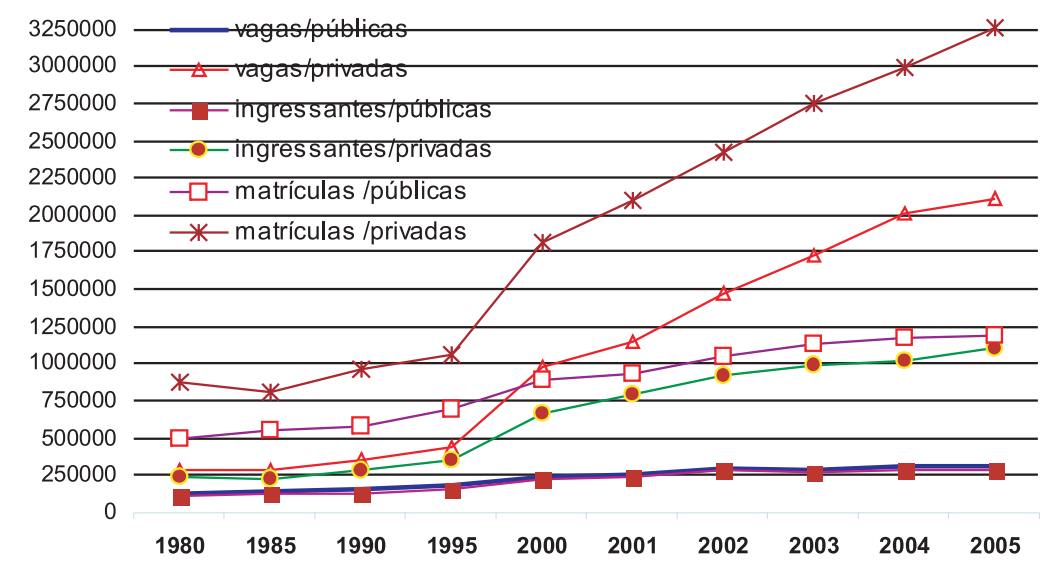

Fonte - INEP/MEC.

Analisando-se os dados apresentados nessa tabela, tendo em conta os alunos que estão no sistema de educação superior, pode-se constatar uma presença de estudantes de renda inferior ( $1^{\circ}$ quinto, $2^{\circ}$ e $3^{\circ}$ quintos) no ensino superior público, ainda que num percentual menor do que na rede privada. A concentração de estudantes pertencentes à parcela mais rica da população é superior a $50 \%$ em ambas as redes: $57 \%$ da matrícula na rede pública e 69,3\% da matrícula na rede privada são ocupadas por alunos oriundos de famílias do quinto mais elevado, que representam apenas 9,6\% das famílias brasileiras, enquanto, apenas 2,3\% e 1,2\% são ocupadas, no ensino público e privado respectivamente, por estudantes mais pobres, oriundos de famílias do $1^{\circ}$ quinto, que correspondem a 30,2\% das famílias do País (PNAD/IBGE, 2004). 
Tabela 10 - Distribuição dos estudantes do ensino médio e ensino superior, por tipo de rede freqüentada, e quintos de rendimento familiar percapta, segundo o Brasil e as Grandes Regiões, 2004.

\begin{tabular}{|c|c|c|c|c|c|c|c|c|c|c|c|c|}
\hline \multirow{4}{*}{ Grandes Regiões } & \multicolumn{12}{|c|}{ Estudantes da rede pública } \\
\hline & \multicolumn{6}{|c|}{ Ensino médio } & \multicolumn{6}{|c|}{ Ensino superior } \\
\hline & \multirow[b]{2}{*}{$\begin{array}{c}\text { Total } \\
\text { (1) }\end{array}$} & \multicolumn{5}{|c|}{ Quintos de rendimento familiar } & \multirow[b]{2}{*}{$\begin{array}{c}\text { Total } \\
\text { (1) }\end{array}$} & \multicolumn{5}{|c|}{ Quintos de rendimento familiar } \\
\hline & & $\begin{array}{c}10 \\
\text { quinto }\end{array}$ & $\begin{array}{c}2^{\circ} \\
\text { quinto }\end{array}$ & $\begin{array}{c}30 \\
\text { quinto }\end{array}$ & $\begin{array}{l}4^{\circ} \\
\text { quinto }\end{array}$ & $\begin{array}{c}50 \\
\text { quinto }\end{array}$ & & $\begin{array}{c}19 \\
\text { quinto }\end{array}$ & $\begin{array}{c}2^{\circ} \\
\text { quinto }\end{array}$ & $\begin{array}{c}3^{\circ} \\
\text { quinto }\end{array}$ & $\begin{array}{l}4^{\circ} \\
\text { quinto }\end{array}$ & $\begin{array}{c}5^{\circ} \\
\text { quinto }\end{array}$ \\
\hline Brasil & 7.990 .350 & 14,9 & 22,2 & 25,4 & 25,2 & 12,3 & 1.205 .822 & 2,3 & 4,8 & 10,3 & 24,9 & 57,7 \\
\hline Norte & 658.947 & 11,6 & 18,3 & 26,4 & 26,2 & 17,5 & 115.483 & 3,9 & 3,9 & 9,0 & 15,3 & 67,9 \\
\hline Nordeste & 2.142 .388 & 13,0 & 19,0 & 24,1 & 26,6 & 17,3 & 345.904 & 1,8 & 2,1 & 6,3 & 15,6 & 74,2 \\
\hline Sudeste & 3.450 .825 & 18,1 & 25,0 & 26,1 & 21,3 & 9,4 & 411.545 & 1,2 & 6,7 & 11,5 & 22,3 & 58,3 \\
\hline Sul & 1.162 .365 & 14,6 & 23,3 & 24,9 & 24,5 & 12,6 & 212.692 & 2,0 & 5,2 & 12,7 & 27,3 & 52,7 \\
\hline \multirow[t]{2}{*}{ Centro-Oeste } & 575.825 & 15,2 & 20,1 & 27,4 & 24,8 & 12,4 & 120.198 & 3,4 & 4,2 & 14,7 & 23,4 & 54,3 \\
\hline & \multicolumn{12}{|c|}{ Estudantes da rede privada } \\
\hline \multirow{3}{*}{ Grandes Regiões } & \multicolumn{6}{|c|}{ Ensino médio } & \multicolumn{6}{|c|}{ Ensino superior } \\
\hline & \multirow[b]{2}{*}{$\begin{array}{c}\text { Total } \\
\text { (1) }\end{array}$} & \multicolumn{5}{|c|}{ Quintos de rendimento familiar } & \multirow[b]{2}{*}{$\begin{array}{c}\text { Total } \\
\text { (1) }\end{array}$} & \multicolumn{5}{|c|}{ Quintos de rendimento familiar } \\
\hline & & \begin{tabular}{|c|}
10 \\
quinto
\end{tabular} & $\begin{array}{c}2^{\circ} \\
\text { quinto }\end{array}$ & $\begin{array}{c}3^{\circ} \\
\text { quinto }\end{array}$ & $\begin{array}{c}4^{\circ} \\
\text { quinto }\end{array}$ & $\begin{array}{c}50 \\
\text { quinto }\end{array}$ & & $\begin{array}{c}10 \\
\text { quinto }\end{array}$ & $\begin{array}{c}2^{\circ} \\
\text { quinto }\end{array}$ & $\begin{array}{c}3^{\circ} \\
\text { quinto }\end{array}$ & $\begin{array}{c}4^{\circ} \\
\text { quinto }\end{array}$ & $\begin{array}{c}50 \\
\text { quinto }\end{array}$ \\
\hline Brasil & 1.381 .091 & 2,5 & 5,0 & 10,7 & 24,4 & 57,4 & 3.375 .882 & 1,2 & 2,1 & 6,6 & 20,8 & 69,3 \\
\hline Norte & 65.300 & 2,7 & 2,2 & 8,6 & 17,9 & 68,6 & 136.769 & 1,6 & 2,8 & 3,5 & 13,9 & 78,3 \\
\hline Nordeste & 332.133 & 2,3 & 2,7 & 8,9 & 19,7 & 66,4 & 479.888 & 1,6 & 1,2 & 3,9 & 11,0 & 82,2 \\
\hline Sudeste & 679.125 & 2,5 & 5,1 & 13,4 & 26,1 & 52,9 & 1.789 .148 & 1,7 & 3,8 & 9,4 & 25,4 & 59,7 \\
\hline Sul & 197.724 & 3,2 & 7,3 & 9,4 & 27,6 & 52,5 & 672.440 & 0,8 & 4,2 & 8,5 & 25,7 & 60,8 \\
\hline Centro-Oeste & 106.809 & 1,8 & 5,8 & 10,4 & 20,4 & 61,6 & 297.637 & 2,5 & 3,6 & 6,9 & 17,7 & 69,3 \\
\hline
\end{tabular}

Fonte - PNAD/IBGE, 2004. Nota: Domicílios particulares. (1)Exclusive pensionistas, empregados domésticos, parentes de empregados domésticos, e pessoas em famílias sem declaração de rendimento.

Nesse sentido, a expansão recente revela que o acesso à educação superior ainda se mostra bastante concentrado nos jovens das camadas de faixas de renda alta e média. Dois aspectos chamam atenção neste processo, além do baixo significado como processo de democratização: a) há uma considerável taxa de evasão, pois, em média, pelo menos $1 / 3$ dos ingressantes não se forma no tempo previsto; b) crescem as dificuldades de parcela significativa dos novos segmentos de alunos para arcarem com os 
Sociologias, Porto Alegre, ano 9, no 17, jan./jun. 2007, p. 124-157

custos do ensino na rede privada, que abriga, como se viu, a maior parcela dos estudantes. Estas situações sugerem a necessidade de se rediscutirem os mecanismos de financiamento da educação superior, as políticas e instrumentos de modernização e qualificação do ensino e de diferenciação da oferta, de modo que haja maior aderência entre essa educação e as expectativas dos estudantes.

Diversificação

Desde a promulgação da nova Lei de Diretrizes e Bases da Educação Nacional em 1996, passou-se a dar maior importância e destaque para a necessidade de diversificação, tanto dos formatos organizacionais como das modalidades de educação superior a serem oferecidas. ${ }^{3}$ Em tese, a diversificação deveria assegurar condições mais favoráveis - menor custo e maior adaptabilidade à demanda - para uma incorporação massiva de novos estudantes. Diversificação deveria ser instrumento, portanto, de democratização do acesso e ampliação da eqüidade.

Com efeito, ao lado da tradicional instituição universitária, com todos os seus problemas, surgiram novos tipos de IES como os centros universitários e centros de formação e educação tecnológica. Diversificou-se, também, a oferta de cursos de duração distinta da tradicional graduação, com a implantação dos cursos seqüenciais de formação específica e cursos tecnológicos (cf. Neves, 2002:47).

Dez anos após o início dessa experiência de diversificação é possível questionar o alcance real das mudanças ocorridas e seu significado como instrumento de democratização. Mesmo assim, tal questionamento não implica negar que estratégias de diversificação dos sistemas de educação superior possam, de fato, ter impacto positivo no processo de ampliação do

3 Cabe destacar três organismos internacionais que vêm desenvolvendo forte reflexão sistemática sobre os sistemas de educação superior: a Unesco, o Banco Mundial e a OECD, propondo a diversificação do sistema como estratégia para a ampliação do acesso. 
Sociologias, Porto Alegre, ano 9, no 17, jan./jun. 2007, p. 124-157

acesso. A experiência internacional parece corroborar esta afirmação com o exemplo de vários países. O Brasil é um caso interessante de estudo, precisamente porque, em boa medida, a diferenciação que ocorreu foi mais na nomenclatura do que na prática.

A diferenciação como campo multifacetado integrado por um conjunto complexo de IES com vocações acadêmicas e perfis organizacionais distintos é uma solução para atender não apenas a demanda, mas também expectativas sociais, acadêmicas e profissionais específicas?

Do total de IES, apenas 11\% (207) são públicas, as demais (1652) são privadas. O Brasil tem um sistema diferenciado de instituições, num total de 1859, sendo 8,8\% universidades, 4,4\% centros universitários, 6,4\% faculdades integradas, $75,5 \%$ faculdades, escolas ou institutos isolados e $5 \%$ centros tecnológicos.

Em relação ao número de matrículas na educação superior por organização acadêmica (ver gráfico 6) e turno, de um total de 4.163 .733 milhões, as universidades, ainda que em menor número, são responsáveis por $57 \%$ das matrículas (sendo que destas, $48 \%$ estão no noturno), ao passo que as faculdades respondem por $22 \%$ do total de matrículas ( $77 \%$ no noturno), seguidas pelos centros universitários com $15 \%$ (com 67\% no noturno), faculdades integradas com 5\% (76,3\% no noturno) e, por fim, os centros de educação tecnológica com $2 \%$ do total de matrículas (63,6\% no noturno).

Aos cursos e programas tradicionais abrangidos pela legislação anterior, graduação, pós-graduação e extensão, a nova LDBN acrescentou a figura dos cursos seqüenciais por campos do saber e os cursos a distância. A modalidade de cursos superiores denominados seqüências são propostos para atender a necessidade de maior inclusão na formação de nível superior com duração mais curta. Segundo Gesteira, buscava-se com essa alternativa:

Ampliar a oferta de vaga dos cursos superiores; flexibilizar o processo de formação de nível superior no país; criar mecanismos para suprir demandas 


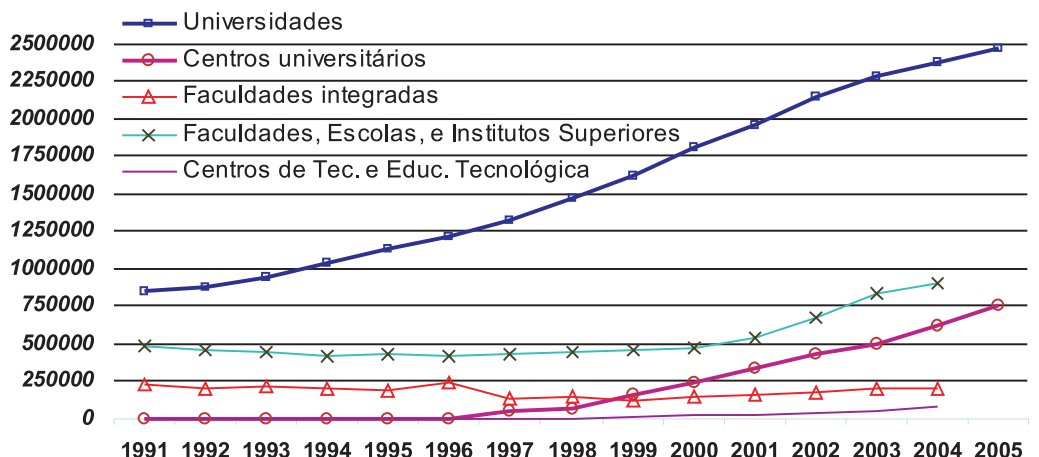

Fonte - INEP/MEC.

emergentes em nichos de mercado não cobertos pelos processos de formação tradicionais; aproveitar vagas remanescentes em disciplinas em cursos de graduação, para introduzir oportunidades de formação pluridisciplinar; introduzir modalidades de formação superior que permitam ampliar as opções atualmente existentes (2001, p. 98).

Em 2001, havia um total de 328 cursos seqüenciais, oferecidos predominantemente por universidades e, na sua grande maioria, privadas. Em 2005 pode-se ver que o número de cursos seqüenciais cresceu consideravelmente. Atualmente são oferecidos, em todo o País, 984 cursos seqüenciais e, embora ainda oferecidos predominantemente por universidades, cresce o número de outras instituições que também passaram a oferecê-los, como os centros universitários e as faculdades integradas.

Por fim, quanto à diversificação, cabe destacar que o sistema oferece relativamente o mesmo tipo de oferta: embora tenham ocorrido mudanças quantitativas, elas não foram qualitativas. Trata-se, apenas de mudanças de nomenclatura e não de mudanças importantes no tipo de oferta de educação superior que poderiam colaborar significativamente para a elevação do 
Sociologias, Porto Alegre, ano 9, no 17, jan./jun. 2007, p. 124-157

acesso e da interação com a sociedade (NEVES, RAIZER, FACHINETTO, 2005).

Políticas afirmativas e de inclusão social

O atual Governo Federal deu prioridade à reforma do sistema da educação superior e buscou enfrentar os estrangulamentos e gargalos do processo de democratização com inúmeras medidas:

a) retomada do crescimento do numero de IES públicas, de modo a aumentar a oferta de vagas públicas através da criação de novas universidades (duas), da consolidação daquela que estava em processo de instalação (uma) e das criadas por transformação (seis) ou desdobramento (duas) e, ainda, ampliação dos campi já existentes. Dentre as criadas, cita-se a Universidade Federal do ABC Paulista, em Santo André, oferecendo 20 mil vagas na graduação e a Universidade Federal do Pampa, na cidade de Bagé, que surge como IES multicampi, oferecendo mais de mil vagas;

b) ampliação do programa de crédito educativo (Fundo de Financiamento ao estudante de Ensino Superior/FIES);

c) destaca-se especialmente, o Programa Universidade para Todos (PROUNI), criado pela MP no 213/2004 e institucionalizado pela Lei no 11.096, de 13 de janeiro de 2005. Tem como finalidade a concessão de bolsas de estudos integrais e parciais a estudantes de baixa renda, em cursos de graduação e seqüenciais de formação específica, em instituições privadas de educação superior, oferecendo, em contrapartida, isenção de alguns tributos àquelas que aderirem ao Programa. No seu primeiro processo seletivo o ProUni ofereceu 112 mil bolsas em 1.142 instituições de ensino superior de todo o país. Nos próximos quatro anos, o programa deverá oferecer 400 mil novas bolsas de estudos; 
Sociologias, Porto Alegre, ano 9, no 17, jan./jun. 2007, p. 124-157

d) implantação de políticas afirmativas, com a reserva de cotas para estudantes negros e um sistema especial de reserva de vagas para alunos egressos de escolas públicas. Essas, no entanto, são medidas polêmicas que têm provocado reações em diversos segmentos do próprio nível superior e na opinião pública (Maggie; Fry, 2004).

Nesse sentido, em relação à política de cotas, a tabela 11 mostra que, em 2003, do total de estudantes brancos de 18 a 24 anos de idade, 46,4\% estavam no ensino superior contra apenas $14,1 \%$ do total dos estudantes negros e pardos. Os dados ainda revelam que, o maior percentual dos estudantes negros e pardos entre 18 e 24 anos, freqüentavam o nível fundamental (30,9\%) ou o médio (49,8\%), o que significa um considerável atraso na escolarização em relação a população branca e ao tempo esperado para conclusão desses níveis de ensino.

Todas essas ações vão ao encontro das metas do Plano Nacional de Educação, que prevê a presença, até 2010, de pelo menos 30\% da população na faixa etária de 18 a 24 anos na educação superior, hoje restrita a $11,5 \%$.

Ainda é cedo para se avaliar o impacto dessas medidas sobre o processo de democratização do acesso, mesmo porque muitas delas não são de aplicação imediata. Dependem de adesão das instituições e, às vezes, de aprovação pelo Congresso Nacional. O acompanhamento de sua implementação - através dos processos de votação, dos arranjos que as instituições precisam fazer para atender as exigências, da equação de financiamento que precisa ser resolvida para assegurar não apenas o acesso, mas também da permanência no ensino superior dos jovens oriundos das camadas sociais de baixa renda, é um componente importante que deve ser objeto de análises e estudos futuros. 
Tabela 11 - Estudantes de 18 a 24 anos de idade, segundo a cor, total e sua respectiva distribuição percentual em relação ao nível de ensino freqüentado, segundo as Grandes Regiões e o país, 2003.

\begin{tabular}{|c|c|c|c|c|c|}
\hline \multirow{3}{*}{ Grandes Regiões } & \multicolumn{5}{|c|}{ Estudantes de 18 a 24 anos de idade, cor branca } \\
\hline & \multirow{2}{*}{ Total (1) } & \multicolumn{4}{|c|}{ Nível de ensino freqüentado (\%) } \\
\hline & & \begin{tabular}{|c|} 
Fundamental \\
ou 1o grau
\end{tabular} & \begin{tabular}{|c|} 
Médio ou \\
2 ograu
\end{tabular} & $\begin{array}{c}\text { Pré- } \\
\text { vestibular }\end{array}$ & \begin{tabular}{|c|} 
Superior ou \\
$3^{\circ}$ grau (2)
\end{tabular} \\
\hline Branca/Brasil & 4.258 .209 & 11,6 & 35,3 & 6,3 & 46,4 \\
\hline Negra, Parda/Brasil & 3.626 .733 & 30,9 & 49,8 & 3,9 & 14,1 \\
\hline Norte (4) (branca) & 155.746 & 17,2 & 46,6 & 7,0 & 29,1 \\
\hline Norte (4) (negra/parda) & 419.888 & 30,9 & 50,9 & 5,2 & 12,0 \\
\hline Nordeste (branca) & 780.343 & 23,5 & 40,8 & 6,8 & 27,8 \\
\hline Nordeste (negra/parda) & 1.792 .587 & 38,6 & 45,7 & 3,9 & 9,9 \\
\hline Sudeste (branca) & 2.117 .679 & 8,9 & 33,2 & 6,6 & 51,2 \\
\hline Sudeste (negra/parda) & 996.939 & 20,6 & 56,7 & 3,5 & 18,8 \\
\hline Sul (branca) & 939.576 & 7,7 & 33,9 & 5,6 & 52,2 \\
\hline Sul (negra/parda) & 125.483 & 20,2 & 52,7 & 4,4 & 20,4 \\
\hline Centro-Oeste (branca) & 263.643 & 9,2 & 34,0 & 4,5 & 51,8 \\
\hline Centro-Oeste (negra/parda) & 282.905 & 22,3 & 48,5 & 3,4 & 25,2 \\
\hline
\end{tabular}

Fonte - PNAD/IBGE, 2003. Nota: inclusive as pessoas sem declaração de anos de estudo. (1) Inclusive a população que freqüentava cursos de alfabetização de adultos. (2) Inclui graduação, mestrado e doutorado. (3) Exclusive a população rural de Rondônia, Acre, Amazonas, Roraima, Pará e Amapá. (4) Exclusive a população rural.

\section{Considerações finais}

É inegável que o sistema de ensino no Brasil mostrou uma expressiva expansão da matrícula em todos os níveis, na última década. É inegável também, que houve uma expansão do acesso ao ensino fundamental, que levou praticamente à universalização da matrícula inicial.

Uma análise mais detalhada dos dados, no entanto, mostra que a pirâmide educacional continua muito aguda. Isto quer dizer que ainda são muito poucos os que concluem o ensino fundamental, menor, ainda, o número dos que concluem o ensino médio e dos que ingressam na educação superior. 
Sociologias, Porto Alegre, ano 9, no 17, jan./jun. 2007, p. 124-157

No caso do ensino básico, todos entram na escola, mas como foi visto, $84 \%$ concluem a 4 a série e apenas $57 \%$ o ensino fundamental. Nesse processo de afunilamento seletivo, no nível médio, o índice de conclusão é de apenas $37 \%$. Cabe ainda acrescentar que os resultados apresentados pelo Sistema de Avaliação do Ensino Básico (Saeb) indicam que a metade dos alunos da 4a série são incapazes de ler um texto simples. Numa comparação internacional, foi constatado que a capacidade de compreensão de leitura dos alunos da elite brasileira é inferior ao nível obtido pelos alunos de classes mais baixas da Europa (SAEB/INEP/MEC, 2005).

Até meados dos anos 90, o crescimento do ensino superior estava praticamente estagnado como mostraram os dados. A partir de 1995, ocorreu um período de forte crescimento nesse nível, sem ocorrer, no entanto, mudanças significativas nos indicadores do nível médio.

A oferta de vagas cresceu, sobretudo no ensino privado, e um contingente de potenciais candidatos, composto de indivíduos que se encontravam fora do sistema de ensino, voltaram a pleitear a oportunidade de realizar um curso superior. Nesse processo, também não se pode menosprezar o impacto do Plano Real e dos ganhos do combate à inflação que abriram novas perspectivas para uma parcela importante da população de classe média baixa. Apesar disso, um aspecto significativo a destacar é que o aumento da demanda por mais ensino superior não significou alteração da estrutura da pirâmide educacional brasileira.

O segundo aspecto é que a lógica do aumento de vagas oferecidas pelo setor privado só aparentemente acompanha a do crescimento da demanda. $\mathrm{O}$ verdadeiro crescimento das vagas oferecidas atende a uma lógica própria de gestão das IES privadas: a oferta de vagas é uma espécie de reserva de mercado preventiva em meio a uma disputa que se foi tornando cada vez mais acirrada, especialmente na região Sudeste. A rentabilidade do empreendimento não depende do pleno preenchimento dessas vagas. 
Sociologias, Porto Alegre, ano 9, no 17, jan./jun. 2007, p. 124-157

A ociosidade é relativa. Ela não reflete necessariamente uma crise do setor. É bem verdade que, de uma perspectiva micro, ou seja, tomando-se instituições isoladamente, é possível que o não preenchimento de vagas desencadeie crise irreversível. Aqui, no entanto, é preciso ter presente que a crise irreversível não se deve ao não preenchimento das vagas a mais, mas sim ao não preenchimento do número mínimo responsável pela rentabilidade básica da IES. Os verdadeiros problemas do setor privado são a concorrência e a dificuldade de se manterem investimentos com vistas à qualificação (que produziria o diferencial, ou vantagem relativa) e a inadimplência. Desta forma, a diferença entre o número de inscritos e o de vagas não parece central para a análise da relação acesso-eqüidade.

A demanda, como se viu, cresce pouco considerando-se o aumento do número de egressos do ensino médio, e mesmo levando-se em conta concluintes fora da faixa etária esperada. Há uma importante contribuição de candidatos oriundos do EJA e de candidatos que estão procurando retornar ao sistema de ensino. Esses são candidatos que já estão no mercado de trabalho.

Considerando-se como meta pertinente à elevação da escolaridade, sobretudo a superior, como um desafio afiançado a idéia de potencialização de um desenvolvimento justo e sustentável, não se pode deixar de considerar que as políticas públicas para o setor devem ter um caráter sistêmico. O processo de democratização do acesso à educação superior, bem como da distribuição mais eqüitativa em termos de gênero, classe e etnia, não pode ignorar que a população brasileira fica, em média, 6 anos na escola e que quase $70 \%$ de seus jovens de 18 a 24 anos não se encontram em nenhum espaço de educação formal.

Com efeito, democratizar o acesso e alcançar uma maior eqüidade na oferta educacional passa pela elevação, não só do tempo de escolarização da população mas, sobretudo, da urgente necessidade de melhorar a qualidade da educação básica que é oferecida. 
Sociologias, Porto Alegre, ano 9, no 17, jan./jun. 2007, p. 124-157

\section{Referências}

BAUMAN, Z. Em busca da política. Rio de Janeiro: Ed. Zahar. 2000.

BRUNNER, J. Educación y Globalización. In: Educação Brasileira. Brasília, DF, 1997.

CASTELLS, M. Sociedade em rede. São Paulo: Paz e Terra, 2000.

CAPES. www.capes.gov.br

DURHAM, E. e SAMPAIO, H. O. O ensino superior em transformação. São Paulo: NUPES, 2001.

GARCIA, G. V. La función social de la educación superior em Méjico. México. UAM, UNAM, Universidad Veracruzana, 2003.

GESTEIRA, C. S. Cursos seqüenciais. In.: DURHAM, Eunice Ribeiro e SAMPAIO, Helena (org.). O ensino superior em transformação. São Paulo: Núcleo de Pesquisas sobre Ensino Superior: NUPES, p.97 - 103, 2001.

GIDDENS, A. A constituição da sociedade. São Paulo: Martins Fontes, 1989.

__. As conseqüências da modernidade. São Paulo: UNESP, 1991.

GUADILLA, C. G. Tensiones y Transiciones. Venezuela: CENDES, Nueva Sociedad, 2002

IANNI, O. A sociedade global. Rio de Janeiro: Civilização Brasileira, 1996.

IBGE. www.ibge.gov.br.

INEP. www.inep.gov.br . www.edudatabrasil.inep.gov.br . www.inep.gov.br/saeb .

MAGGIE, Y.; FRY, P. A reserva de vagas para negros nas universidades brasileiras. In: Estudos Avançados, N.o 50: São Paulo, 2004.

MARTINS, R. O. Cursos Seqüenciais: entendendo a formação de curta duração. Bauru, São Paulo: EDUSC, 2004.

MEC. www.mec.gov.br.

.SeSu. www.educacaosuperior.inep.gov.br . 
Sociologias, Porto Alegre, ano 9, no 17, jan./jun. 2007, p. 124-157

NEVES, C. E. B. A estrutura e o Funcionamento do ensino superior no Brasil. In: Soares, M. S. A. (Org.) A educação superior no Brasil, Brasília: UNESCO/CAPES/ GEU, p. $43-69,2002$.

.Diversificação do Sistema de Educação terciária: um desafio para o Brasil. In: Tempo Social. Revista de Sociologia da USP. V. 15, n. 1, maio 2003.

. RAIZER, L; FACHINETTO, R. F. Diversificação do sistema de ensino superior: um novo cenário? Relatório de pesquisa/CNPq, 2005.

SANTOS, B. S. (Org). A globalização e as Ciências Sociais. São Paulo: Cortez, 2002.

UFRGS . Documento sobre os cursos seqüenciais. CEPE (Câmara de Ensino e Pesquisa) UFRGS,1999.

SCHWARTZMAN, S. Equity, quality and relevance in higher education in Brazil. In: Anais da Academia Brasileira de Ciências, 2004.

\section{Resumo}

No Brasil apenas 11,5\% dos jovens entre 17 e 24 anos conseguem chegar ao ensino superior. Como ampliar o acesso e alcançar uma maior eqüidade, com uma formação de qualidade, é uma questão central da política educacional. Na última década, foram propostas soluções referentes à ampliação do acesso e maior eqüidade através da diversificação do sistema com a criação de novos tipos de IES, novos tipos e modalidades de cursos, bem como da proposta de políticas inclusivas e de ações afirmativas (PROUNI e política de cotas). A análise de dados estatísticos, entrevistas, documentos, legislação revelam o cenário atual: a ampliação do acesso, bem como a implantação de políticas de inclusão deram-se, especialmente, pelo sistema privado de educação superior, produzindo um efeito socialmente perverso de democratização.

Palavras-chave: Educação superior, diversificação, eqüidade, política educacional. 
Sociologias, Porto Alegre, ano 9, no 17 , jan./jun. 2007, p. 346-352

Access, expansion and equity in Higher Education: new challenges for educational policy

Clarissa Eckert Baeta Neves, Leandro Raizer,

Rochele Fellini Fachinetto

Higher education has entered the list of priorities and strategic topics for the future of nations: there is widespread belief that development requires an increase in the population's educational levels. In Brazil, however, only $11.5 \%$ of 17-24year-olds reach higher education. How to increase access and achieve more equity with quality education is a core issue for educational policy. In the last decade, solutions were proposed for more access and equity by diversifying the system through the creation of new kinds of Higher Education Institutions, new kinds and modalities of courses, as well as affirmative action policies (PROUNI e quota policies). The analysis of statistical data, interviews, documents, and legislation reveals the current scenario: broader access as well as the establishment of inclusion policies took place mainly through the private educational system, thus generating a socially unjust effect on democratization.

Key words: higher education, diversification, equity, educational policy. 